\title{
C) CitcastórRICA
}

\section{Considerações críticas acerca das teorias de Raewyn Connell e Judith Butler para o estudo das masculinidades}

\author{
Consideraciones críticas acerca de las teorías de Raewyn Connell y Judith Butler para la \\ investigación de las masculinidades
}

Fernando Bagiotto Botton"

Resumo: Realizaremos um despretensioso balanço crítico de algumas possibilidades teóricas sobre a questão da masculinidade a partir de um diálogo por nós estabelecido entre a socióloga Raewyn Connell e a filósofa Judith Butler. Iniciaremos nosso texto com algumas dúvidas com relação à forma com que estudamos as masculinidades contemporaneamente, num conjunto de reflexões de fundamento epistemológico que, ao nosso ver, possuem poucas respostas, mas que atravessam as problemáticas lançadas pelas pesquisadoras debatidas. Passaremos para uma crítica à teoria das masculinidades hegemônicas de Connell para então apresentar algumas possibilidades de análises que podem ser apropriadas da teoria queer de Butler. Por conseguinte, tentaremos traçar alguns pontos de confluência entre as leituras mais recentes realizadas por Connell e sua relação epistemologicamente tensa mas politicamente paralela com os estudos de Butler.

Palavras-chave: masculinidades; teoria; gênero.

Resumen: Realizaremos un estudio crítico poco pretensioso acerca de algunas posibilidades teóricas acerca de la cuestión de la masculinidad a partir de un diálogo establecido por nosotros entre la socióloga Raewyn Connell y la filósofa Judith Butler. Empezaremos nuestro texto con algunas dudas con relación a la manera con que estudiamos las masculinidades contemporáneamente, en un conjunto de reflexiones de fundamento epistemológico que, a nuestra perspectiva, poseen pocas respuestas, pero que cruzan las problemáticas lanzadas pelas investigadoras debatidas. Pasaremos a una crítica a la teoría de las masculinidades hegemónicas de Connell para entonces presentar algunas posibilidades de análisis que puedan ser apropiadas

\footnotetext{
* Doutor em História pela Universidade Federal do Paraná - Linha Intersubjetividade e Pluralidade: Reflexão e Sentimento na História, com Estágio de Doutorado Sanduíche na Universidad de Buenos Aires (UBA) (PDSE/CAPES). Professor Adjunto I (DE) e Coordenador do Curso de Licenciatura Plena em História da Universidade Estadual do Piauí (Campus Alexandre Alves de Oliveira - Parnaíba-PI).
} 


\section{C) Hitistótórica}

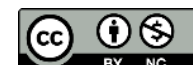

de la teoría queer de Butler. Por consiguiente, tentaremos trazar algunos puntos de confluencia entre las lecturas más recientes realizadas por Connell y su relación epistemológicamente tensa, pero políticamente paralela con las investigaciones de Butler.

Palabras-clave: masculinidades; teoría; género.

\section{O problema das adjetivações - dúvidas}

O importante livro de Pedro Paulo de Oliveira intitulado: A construção social da masculinidade (2004) buscou conceituar o termo masculinidade enquanto "um lugar simbólico/imaginário de sentido estruturante nos processos de subjetivação [...] uma significação social, um ideal culturalmente elaborado ou sistema relacional que aponta para uma ordem de comportamentos socialmente sancionados" (2004, p. 13). Nessa sofisticada colocação se lega protagonismo à questão simbólico-discursiva mas, igualmente, constitui um campo interpretativo da masculinidade aparte dos demais estudos de gênero. Desde essa concepção, já podemos perceber uma tensão inerente às opções teóricas e epistemológicas ofertadas para compreender o fenômeno da masculinidade: por um lado uma perspectiva de caráter mais sociológico de conceber o gênero a partir das práticas e engendramentos sociais, e por outro a perspectiva mais linguística, filosófica e psicanalítica que concebe o masculino enquanto construção discursivo-simbólica, nomeado pelas teias reiterativas de poder-saber. Essa tensão, já presente no texto de Oliveira será um dos grandes impasses relativos às contraposições entre as duas teóricas aqui estudadas. Não buscaremos unir ambos os conceitos ao propor uma síntese, no caminho do que fez Oliveira ao abranger tanto as práticas quanto os discursos, antes disso gostaríamos de compreender alguns meandros dessa discussão que, poderá ser de alguma relevância para a reflexão teórica dos estudos acerca das masculinidades.

Dessa forma, compreendemos que trabalhar de antemão com um conceito de masculinidade, mesmo que plural, como masculinidades já é, elementarmente, tarefa com grandes chances de fracasso interpretativo. Isso porque o próprio termo masculinidade, se tomado enquanto um fato social evidente, aponta para um rol de características, de atitudes, de traços de personalidade referente às pessoas, ações ou ideias, que se costuma adjetivar - viril, másculo, potente, hombridoso etc. - mas com pouca explicação de sua origem fenomenal ou epistêmica. Atualmente, os grandes ganhos que se conseguem alcançar pela descrição de 


\section{G) GitsTórilcA}

características de masculinidade nas ciências humanas e sociais são esses adjetivos: qualidades, modelos do que seria compreendido enquanto aquilo que é pré-definido enquanto masculino. O que facilita o trabalho da pessoa que pesquisa, mas dificulta a definição mais precisa de um conceito científico que se furte da apropriação daquilo que já seria popularmente concebido enquanto masculino.

A oposição realizada por Simone de Beauvoir ao colocar o feminino como segundo sexo (20I2), já que o masculino seria o primeiro, abriu grandes perspectivas de compreensão crítica do gênero, em especial a dificuldade da aproximação teórica a um conceito como a masculinidade que já haveria de ser considerado enquanto previamente dado, universalmente aceito, estabelecido por si só, impassível de ser refletido, conceituado, pensado e, por consequência, criticado. Tal dificuldade de aproximação conceptual justifica a opção de Robert/Raewyn Connell ${ }^{1}$ de pluralizar o termo e tratar sempre de masculinidades, já que na falta (e talvez até na contrariedade) a um conceito centralizador de sentidos prefere-se trabalhar com a insígnia da pluralidade. Desta forma Connell nos transmite a noção de que a masculinidade seria um fenômeno existente no campo das práticas, ações, experiências e fazeres em sua efetividade social. Nesse sentido os processos de hierarquização, violência e exclusões de gênero ocorreriam a partir das práticas sociais econômicas e historicamente delimitadas que legitimariam posições sexuadas de superioridade e inferioridade. Por outro lado, a noção mesma de masculinidade enquanto um conjunto unificador de valores e experiências sociais relativamente abrangente à todas as sociedades, mesmo que se respeite suas pluralidades, não é exatamente um objeto que possua sua existência de maneira teorizada, não é delimitável ou palpável anteriormente à prática contextualmente analisada pelo pesquisador, não se adapta em uma identidade conceptual ou mesmo característica. Mesmo com toda essas contingencialidades e contextualismos, nada impede de que se siga agrupando essas práticas sob a insígnia do macroconceito masculinidade, seja no singular ou no plural. Isso pode gerar algumas dúvidas quanto ao estatuto epistemológico da própria conceituação de masculinidade enquanto um unificador de todas as experiências sociais do mundo relacionadas às distintas e diversas experiências de gênero, sem que se haja um substantivo por trás desse aglutinador mas

\footnotetext{
I Robert William era o nome masculino de Connell, anteriormente à sua transformação ao gênero feminino, passando então a ser chamada de Raewyn. Na dificuldade de adequação normativa optamos por utilizar o nome de Robert para referenciar publicações concernentes à época em que Connell assinava seus textos com tal nomenclatura e Raewyn nos textos em que assumiu sua nomeação feminina.
} 


\section{C) CitcastórRICA}

um conjunto de adjetivos, que, por si só, já são culturalmente estabelecidos e impassíveis de responder a conceituações universalistas.

Levando isso em consideração, muitas vezes nos sentimos desestimulados de utilizar o conceito de masculinidade em nossas pesquisas, justamente porque nas análises heurísticas tudo o que conseguíamos alcançar partia de um apelo a um conjunto de características adjetivas que delimitavam antes um jogo de atributos daquilo que seria teorizado pelo pesquisador enquanto masculino (viril, macho, forte, hombridoso etc) do que por um substantivo que pudesse definir de antemão a constituição do que seria compreendido elementarmente enquanto masculinidade. Mais que isso, é possível questionar-se eticamente se as próprias pesquisas que buscavam conceituar e construir um papel e um escopo para a masculinidade não estariam, no momento de sua crítica, tornando possível e tangível um substantivo de masculinidade - antes inexistente - que em sua própria conceituação unificaria esse conjunto de adjetivos em uma identidade prévia (o ser-masculino) reforçando padrões desiguais de gênero e afirmando certa homogeneização de práticas masculinas sem levar em consideração a pluralidade dessas práticas e a impossibilidade prévia de se definir o que seria precisamente compreendido enquanto masculino.

Parece que se afigura um ciclo vicioso: conceituam-se masculinidades como um conjunto de jogos de práticas na sociedade para, assim, entender esse jogo de práticas, de forma semelhante a um duplo empírico-transcendental em que não há uma âncora externa à própria formulação autorreferente (FOUCAULT, 2007). Mais problemático ainda é quando o conceito tende a aceitar, de antemão, uma dicotomia masculino-feminino de maneira naturalizada, que está longe de estar aceita pelos estudos de gênero. Afinal, fundar um conceito de masculinidade polarizado em um dos lados da esfera dicotômica dos sexos já seria, a priori, validar uma oposição direta à feminilidade, consequentemente aceitando não apenas o sistema dicotômico do dimorfismo sexual moderno (LAQUEUR, 200I) mas também a própria essência de qualificativos específicos que designariam aquilo que seria compreendido enquanto o masculino e o feminino. Contra tal perspectiva, à primeira vista essencialista e dicotômica, se poderia trabalhar por uma perspectiva anárquica que afira que:

a masculinidade não existe, enquanto característica, traço de caráter ou aspecto da identidade dos indivíduos. Isto quer dizer que tentar definir uma ou várias 


\section{C) ChitsisTórICA}

masculinidades é uma tarefa infrutífera [...] Ela existe apenas como ideologias ou fantasias variadas" (MACINNES, I998, p.2).

Mesmo que seja uma posição teoricamente sensata dado seu caráter crítico e desconstrucionista, acreditamos que poucas pessoas que pesquisam a temática estariam dispostas a simplesmente abandonar o intuito de utilizar o conceito a ponto de tirar alguma significação efetiva, para além das fantasias variadas, até porque, mesmo as fantasias têm seus impactos e consequências nas vivências coletivas. Dessas interrogações, teremos que admitir que até então não há na ideia de masculinidade ou masculinidades nenhuma materialidade préfigurativa ou elemento extra-empírico que o assegure enquanto fato social teoricamente autoevidente. Nesse sentido, não há substantivo para além dos adjetivos, toda abordagem será específica, sem qualquer possibilidade de invariáveis contextuais (geográfica ou historicamente falando) o que impossibilitaria conceituar a masculinidade enquanto um fenômeno universalmente aplicável. Ter consciência dessa espécie de fraqueza epistemológica do conceito talvez seja o primeiro passo para tentarmos fortalecê-lo enquanto algo científico - que enquanto tal é consciente de seus limites epistêmicos, mas que compreenda seus pressupostos. Com isso evitaríamos utilizar a clássica estratégia de citar um par de passagens de A dominação masculina de Bourdieu (1997) e Políticas da Masculinidade de Connell (1995) como referenciais e assim dar por sentada a questão teórica, nos sentindo autorizados a avançar para o estudo de virilidades, machismos, hegemonias ou supremacias nas metodologias históricas, sociológicas, etnográficas e nas demais manifestações de práticas/significações sociais.

Isso não significa que demandamos por um conceito transcendental de masculinidade, que mantenha um pressuposto teórico universalmente aplicável enquanto dado previamente estabelecido. Tampouco podemos antecipar uma interpretação específica sobre as masculinidades com relação à análise empírica do objeto de estudos sob o risco de simplesmente comprovar a teoria já estabelecida sem compreender as particularidades internas em cada contexto. É nesse sentido mais interrogativo e questionador que pretendemos trazer uma breve crítica apropriativa com relação às teorias da masculinidade hegemônica de Robert/Raewyn Connell, possibilitando que alguns de seus flancos possam ser protegidos se pensados a partir das teorias de Judith Butler como um possível amparo teórico à delicada questão da masculinidade adjetivada, uma vez que a autora compreende o gênero por uma perspectiva anti-identitária que conjuga pelo conceito de performatividade tanto os pressupostos 


\section{C) Gitsơ TórICA}

de uma teoria de gênero/subjetividade abrangente quanto a positividade efetiva dos atos e exercícios de fazer, refazer e desfazer o gênero e o masculino. Mesmo por meio dessa proposta interpretativa, estamos cientes que grande parte das dúvidas aqui levantadas permanecem e permanecerão em suspenso.

\section{Masculinidade e hegemonia - críticas}

Travar contato com a teoria das masculinidades de Robert Connell é inevitável para qualquer pessoa que pretenda pesquisar a temática. O livro Masculinities (I995) ${ }^{2}$ é, certamente, o primeiro texto a ser recomendado para discentes que pretendam iniciar seus estudos acerca da temática, não apenas por que se trata de um clássico e sua abordagem pluraliza a(s) masculinidade(s), mas também porque foi um estudo empiricamente aprofundado e pioneiro, rompeu com a teoria dos papéis sociais - predominante nas abordagens psicológicas da época - e mesclou de maneira interdisciplinar marxismo, psicanálise, teoria de gênero e, posteriormente, pós-colonialidade, para forjar uma conceituação bastante potente, capaz de estabelecer contrastes entre aquilo que foi tratado enquanto masculinidade hegemônica em oposição ao que passou a compreender enquanto masculinidades subalternas. Dessa teorização se propagaram de forma intensa e mundial os men studies, estabelecidos como um novo paradigma aos estudos de gênero. Desde a publicação seminal de Connell (I995), muitas críticas lhes foram dirigidas, grande parte delas rebatidas no artigo de revisão intitulado Masculinidade hegemônica: repensando o conceito, que escrevera em parceria com James Messerschmidt (2013). De todas as formas, mesmo após tais réplicas e tréplicas ainda se mantém certo escopo principal que permeia a teoria das masculinidades hegemônicas e subalternas da qual realizaremos, nós também, algumas críticas pontuais para abrirmos espaço para a adscrição de outras teorizações e perspectivas hermenêuticas.

Segundo Connell, o conceito de masculinidade significa "un lugar en las relaciones de género, en las prácticas en las cuales los hombres y las mujeres ocupan ese espacio en el género"3 (2003, p. 109). A amplitude dessa definição é sua melhor marca, trabalha de maneira relacional e aplica todo foco na noção de práticas, delimitando seu caráter evidentemente empírico e

\footnotetext{
${ }^{2}$ Traduzido para mais de 13 línguas (HAMLIN; VANDENBERGHE, 20I3).

3 T. do A. "um lugar nas relações de gênero, nas práticas em que os homens e as mulheres ocupam esse espaço no gênero".
} 
sociológico. Por outro lado, uma possível debilidade dessa concepção é que define a masculinidade como uma posição na relação de gênero, mas não define explicitamente o que compreende por homens e mulheres, de certa forma podemos dizer que, no intuito de valorizar o empírico prescinde de uma teoria de gênero como norteadora. Parece que os substantivos são tomados como elementos previamente estabelecidos, sem levar em consideração que o gênero é justamente anterior e formulador daquilo que conhecemos e categorizamos enquanto homens e mulheres. Evidentemente isso não abala sua teoria como um todo, já que a preocupação parece não ser necessariamente definir uma concepção, mas antes disso, estabelecer um solo epistemológico-sociológico em que as práticas corporais, as relações de dominação e a violência possam ser compreendidos analogamente por pesquisas que pretendam deslindar as manifestações práticas de indivíduos nesses territórios de gênero, construídos no interior de uma determinada sociedade. Porém, isso não impediu que alguns teóricos estabelecessem algumas críticas, como a seguinte:

É exatamente nesse momento, em que o sociólogo pretende firmar uma posição relativista que, paradoxalmente, acaba retornando à essencialização da masculinidade agora ancorada no local pré-discursivo das ações sociais conscientes. Ao localizar a masculinidade nas práticas individuais [e sociais] Connell acaba misturando o empírico e o transcendental em favor do segundo [...]. É evidente que tal mistura é efetivamente exercida no campo das práticas sociais e a masculinidade, mesmo como invenção, têm suas positividades nessa área. A questão é que ao teorizar nesse modelo Connell acaba reafirmando essa confusão entre um conceito abstrato e normativo [masculinidade] e as práticas sociais individuais. Nessa teorização connelliana a masculinidade passa a ganhar uma posição própria, ainda se mantém no campo estrutural e, justamente por ser uma prática, torna-se fundamentalmente material, real, idêntica, representável e analisável em sua expressão legítima a partir das ações humanas, seja dos homens ou seja das mulheres. A estratégia connelliana busca implicações funcionais na esfera política, uma vez que retira a masculinidade do campo do natural e a insere no campo das ações individuais. De substantivo e adjetivo a masculinidade passou a ser verbo, o que lhe dá melhor dinâmica e fluidez: isso faz com que a masculinidade multiplique seus significados a partir das ações individuais, passando a ser tratada em seu formato plural, como masculinidades. A questão que colocamos é que essa 


\section{G) Citsistórica}

teoria não nos parece radical o suficiente, já que o pesquisador não desdobrou sua teoria da multiplicidade até o momento em que as masculinidades se ramificassem cada vez mais, o que em última escala a dissolveria por completo no bojo infinitesimal das ações mundanas. Pelo contrário, deste sorvo das ações Connell recria apenas quatro categorias para classificar, ordenar e abranger todas as existências sociais masculinas em sua conotação prática (BOTTON, 2OII: 52-53)

Essa crítica de duas pontas e bastante datada, do início da segunda década do século XXI, parece ter pretendido, em primeiro lugar, questionar a tomada do conceito de masculinidade a partir das práticas pelo fato de que isso acaba legitimando a primeira pela segunda. Em segundo lugar, parecia questionar o sociologismo categórico em que Connell encerrava as masculinidades nas tags de: hegemônicas, subordinadas, cúmplices e marginais (CONNELL, 2003: IO9-II5). É importante ressaltar que, por mais que essa crítica aponte certas inflexibilidades na teoria connelliana ela é menos operatória atualmente por conceber seus conceitos como monolíticos, estáticos e com pouca dinâmica. Pelo contrário, Connell neutralizou muito dessas críticas quando apresentou novas respostas em escritos mais recentes (CONNELL; MESSERDCHMIDT, 20I3) que, nas primeiras críticas, não puderam ser levadas em consideração. De maneira bastante enfática, Connell mantém firme sua posição no entorno da questão da masculinidade como prática, elemento do real, afastando qualquer pretensão de diálogo com as leituras simbólicas, linguísticas e/ou pós-estruturalistas, como as de Judith Butler. Por outro lado, afirma a variabilidade de sua teoria, pluralizando-a de maneira aberta, trazendo não apenas novas contribuições com relação à maleabilidade de seus conceitos, mas também avança a discussão no sentido de pensar as masculinidades não apenas historicamente - na verdade com um tom um pouco historicista - mas também espacialmente, ocasião em que buscou compreender interessantes jogos de escalas entre masculinidades locais, regionais e globais, que refletem nas estruturas sociais, de gênero e de poder a partir de categorias não mais universalistas, mas que compreendem as especificidades de outras regionalidades (CONNELL; MESSERDCHMIDT, 20I3).

Esse novo fôlego presente em sua teoria faz de suas pesquisas ainda uma grande ponta de lança nos estudos sobre as masculinidades, todavia segue sendo uma ferramenta teóricometodológica mais apropriada para pesquisas de caráter mais empírico-sociológico, fornecendo uma grade interpretativa razoavelmente maleável para a compreensão de estruturas de poder, 


\section{G) hitsTórica}

especialmente eficaz para as sociedades modernas-capitalistas. Por outro lado, ainda não responde enquanto uma teoria harmonicamente integrada aos estudos de gênero para definir o que se concebe enquanto um homem justamente porque para Connell o homem é dado anteriormente às práticas de construção de gênero, sendo a masculinidade um produto das ações dos homens, e não a constituição própria de suas existências. Isso é tranquilamente defensável, mas transmite a impressão de que os estudos feministas e suas teorizações são preteridos e apartados dos men studies, de forma que as citações de pesquisas comprobatórias da teoria das masculinidades hegemônicas sustentassem empiricamente tudo aquilo que uma longa tradição de questionamentos das segundas e terceiras ondas feministas responderam por outras discussões, bastante acaloradas, acerca a constituição do gênero - para além das puras práticas sociais.

Asseveramos que essa crítica não põe em xeque a teoria das masculinidades hegemônicas, sob o ponto de vista do construcionismo social a posição de Connell é absolutamente coerente, uma vez que concebe a existência de indivíduos de ação e consciência que por meio de suas experiências e práticas estabelecem padrões coletivos e hierárquicos de gênero: $a(s)$ masculinidade(s). A crítica aqui levantada apenas faz sentido se pensada sob a perspectiva pós-estruturalista já que compreende como um risco a afirmação de um homem anterior às práticas performativas de constituição do gênero. Para a ótica butleriana, conceber tal homem de maneira pré-discursiva possibilitaria epistemologicamente a existência de uma materialidade originária e natural daquilo que é tido enquanto homem. Nesse sentido a masculinidade passaria a ser apenas um suprassumo identitário que confirmaria coletivamente posições dicotômicas, individuais, inalteráveis e pré-estabelecidas de gênero. Sob tal olhar crítico pós-estruturalista, seria possível criticar não apenas o caráter hegemônico das masculinidades, mas, antes disso, criticar-se-ia o próprio conceito de masculinidade como uma agrupação de práticas individuas que verteriam do interior das ações de indivíduos préconcebidos em sociedade, sem que houvesse estrutura simbólica, linguística, epistemológica e discursiva que constituísse o sujeito-homem. O que estaria em jogo nessa crítica é a rigidez das definições de gênero, uma vez que a concepção connelliana compreende a masculinidade enquanto manifestação prática da ação desses homens em esfera social. Pela crítica pósestruturalista tais homens não haveriam de existir previamente constituídos e estabelecidos, uma vez que essa posição construcionista social os colocaria como incapazes de serem desconstruídos, reconstruídos ou destituídos de suas posições, hierarquias e padrões de gênero. 


\section{G) GitșTórICA}

Por fim, mesmo que consideremos a definição de masculinidades de Connell como uma das mais aprofundadas teoricamente e, certamente, a mais citada, ponderamos que ela não deve - assim como nenhuma outra teoria - ser considerada definitiva com relação ao estabelecimento efetivo de um conceito ontológico-político do termo, não apenas porque evita contemplar elementos linguísticos, simbólicos e discursivos em seu escopo, mas também pelo fato de que a identificação de masculinidades hegemônicas e subalternas também não resolve todas as dinâmicas que a noção de masculinidade pode assumir. É evidente que o conceito é prontamente operacional uma vez que as próprias manifestações práticas daquilo que os pesquisadores chamam por masculinidades se definem por meio de estratificações sociais hierárquicas, portanto sempre haverá posições de poder e subalternidade. Por outro lado, pouco se fala nos locais simbólicos pré-práticos da noção, isto é, um locus apriorístico de onde seria derivada a constituição das lógicas dessa estrutura de gênero, que apontaria seus manuais de montagem e desmonte. Embora que essa questão fica em aberto na teoria connelliana, as críticas aqui tecidas não inviabilizam uma vírgula de suas pesquisas e muito menos daqueles que se apoiam em suas teorias para fazê-las. O conceito de masculinidade hegemônica segue atuando como norteamento teórico possível: qualquer etnografia demonstra que tais práticas podem ser consideradas relacionadas ou constituintes das masculinidades em determinadas sociedades. Tal abordagem serve, sobremaneira, à epistemologia sociológica e, em menor escala, antropológica que possuem certas proximidades empíricas (em esferas temporais e/ou espaciais) do pesquisador com seu objeto de estudos. Por outro lado, caso queiramos pensar no conceito de masculinidade(s) de maneira transdisciplinar e também historiográfica é necessário que recorramos a outros itinerários teóricos, não apenas no sentido de ampliar seu escopo mas de encontrar pontos de contato entre a teoria das masculinidades connellianas com as demais linhas dos estudos de gênero, especialmente o feminismo linguístico e a teoria queer.

\section{Pensando a masculinidade a partir de Butler - Possibilidades}

Em momento algum a filósofa Judith Butler pretendeu realizar uma interpretação ou teorização sobre a questão da masculinidade. Seus poucos escritos dedicados ao gênero, especialmente os livros Bodies that matter: on the discursive limits of "sex" (I993) e Problemas de Gênero: feminismo e subversão da identidade (2019) - publicado originalmente em inglês no ano de 1990 - referem-se mais especificamente a uma crítica de caráter pós-estruturalista à 
epistemologia feminista, especialmente identitária, objetivando garantir espaços de reflexão para além dos feminismos liberal ou radical ${ }^{4}$. É justamente por meio da apropriação e derivação dessas críticas de Butler que nos valeremos para propormos outras possibilidades teóricas aos estudos das masculinidades. Trata-se de compreensões ancoradas em alguns conceitos butlerianos para refletir sobre a relação entre gênero e masculinidade, talvez sanando algumas das lacunas teóricas deixadas pelas primeiras pesquisas de Connell. Tal aproximação entre Butler e a masculinidade não se apresenta como uma novidade, outros pesquisadores já o fizeram (BRICKELL, 2005 e KELLER; ARAUJO, 20I7), mas acreditamos que levantar alguns de seus pontos essenciais é importante para estabelecermos contrastes e aproximações com as teorias connellianas, apresentando novas perspectivas sobre o estudo das masculinidades.

Butler buscou suas ferramentas teóricas em filósofos/linguistas como Jacques Derrida (I99I) e John Austin (I955), dentre muitos outros, para criar seu diagnóstico da produção dos sexos $^{5}$ enquanto performatividade (RODRIGUES, 20I2). Austin fez uma grande mudança no campo dos estudos linguísticos na década de 1950 ao propor que as orações ao serem pronunciadas podem ser consideradas ações. Em seu livro Cómo hacer cosas con palavras (2016) Austin delimitou uma série de sentenças que ele considerava performativas justamente porque além de expressar coisas são, em si próprias, atos de fala [speech acts]:

emitir la expresión es realizar una acción y que ésta no se concibe normalmente como el mero decir algo. [...] expresar las palabras es, sin duda, por lo común, un episodio principal, si no el episodio principal, en la realización del acto (de apostar o de lo que sea), cuya realización es también la finalidad que persigue la expresión ${ }^{6}$ (AUSTIN, 20I6, p. 06-08).

\footnotetext{
${ }^{4}$ Embora não seja o intuito desse artigo, é importante ressaltarmos que a publicação original de Gender Trouble: Feminism And the Subversion of Identity (1990) de Butler é cinco anos anterior à publicação do texto de Connell (I995). Mesmo que naquela época suas pesquisas eram pouco vinculadas, ambas foram muito importantes para influenciar toda uma geração de intelectuais que praticamente inauguravam a temática das masculinidades no contexto brasileiro, dentre muitos podemos citar as pesquisas de OLIVEIRA (2004), CECCHETTO (2004), MATOS (200I), MONTEIRO (2000), SOUZA (2003), ALBUQUERQUE JÚNIOR (2003).

${ }^{5}$ Para a autora, como não há um lugar biológico neutro, pré-discursivo que garanta a naturalidade do sexo, ambos os termos podem ser tomados como sinônimos (BUTLER, I993).

6 "Emitir a expressão é realizar uma ação, e esta não se concebe normalmente como um mero dizer algo. [...] expressar as palavras é, sem dúvida, comumente, um episódio principal, se não for o episódio principal, na realização do ato (de apostar ou do que seja), cuja realização é também a finalidade que persegue a expressão" ( $T$. do A.).
} 


\section{C) HitșTórICA}

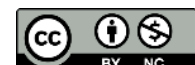

Para o filósofo, pronunciar algo já produz o efeito linguístico de um ato, isso é semelhante às formulações de Derrida quando anuncia que "escrever [e enunciar] é produzir uma marca que constituirá uma espécie de máquina, produtora" (DERRIDA, I99I, p. 20). Trata-se do ato de escrever ou citar algo e de reiterar essa citação como a instituição do próprio ato, que para o filósofo não é fruto de uma vontade individual, mas é derivativo da linguagem: "Nesta tipologia a categoria de intenção não desaparecerá, ela terá seu lugar, mas a partir deste lugar, não poderá mais comandar todo o sistema e toda a cena de enunciação" (DERRIDA apud BUTLER, 20Io, p. I67). Nessas formulações, Austin e Derrida não definem um sujeito mentor destes atos de linguagem, mas, pelo contrário, uma linguagem mentora do sujeito que fala. Não que sua decisão não seja efetiva, mas este sujeito não possui o total domínio de sua enunciação frente à ordem discursiva na qual enuncia, uma vez que tal sujeito já está previamente inserido nela, nas condições e regras do que pode e do que não pode ser dito ou aceito.

A partir destas premissas Butler demonstra que "o discurso adquire a autoridade para produzir o que nomeia através da citação das convenções e da autoridade” (20I0, p. I76). Por meio de suas leituras acerca do psicanalista Jacques Lacan, a autora compreende que o poder das normas se relaciona diretamente com a citação da lei que a institui performaticamente como um ato de fala. Esse é um círculo vicioso uma vez que "a lei não é mais dada em uma forma fixa, anteriormente à sua citação, mas é produzida através da citação, como aquilo que precede e excede as aproximações [...] efetuadas pelo sujeito" (BUTLER, 20Io, p. I69). Em outras palavras, a própria norma que institui a heterossexualidade, enquanto heteronormatividade, é dada através de um processo linguístico e discursivo de citação, nomeação ou mesmo enunciação. É assim que, para Butler, o sexo e o gênero são construídos: a partir de um ato de fala ou de uma performatividade, entendida como "a prática reiterativa e citacional pela qual o discurso produz os efeitos que ele nomeia" (20I0, p. I54). Tal ação se torna política e criadora a partir do momento que “as normas regulatórias do 'sexo' trabalham de uma forma performativa para construir a materialidade dos corpos e, mais especificamente, para materializar a diferença sexual a serviço da consolidação do imperativo heterossexual" (BUTLER, 20IO, p. I54).

Nesse contexto de performatividade, a noção de natureza perde sua posição de verdade ou de ser pré-discursiva, já que "o social atua unilateralmente sobre o natural e o investe com seus parâmetros e seus significados" (BUTLER, 20I0, p. I54). Assim é implodida a diferenciação entre o campo natural e o campo social/cultural, especialmente se tratarmos das concepções 


\section{C) GitșTórICA}

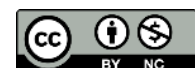

hierárquicas e sexuais na sociedade moderna. Em outras palavras, pensar a natureza como uma parte construída da cultura significa que a própria dicotomia entre gênero (como a diferença dos sexos produzida de forma social/cultural) e sexo (como a diferença dos sexos produzida de forma natural) perde toda sua validade, uma vez que o primeiro absorve o segundo e demonstra sua inconsistência enquanto verdade universal:

Quando a distinção sexo/gênero se junta a um construcionismo linguístico radical [...] o "sexo" [...] será ele mesmo uma postulação, uma construção, oferecida no interior da linguagem, anterior à construção. Mas esse sexo colocado como anterior à construção torna-se, em virtude de ser assim colocado, o efeito daquela mesma colocação: a construção da construção. Se o gênero é a construção social do sexo e se não existe nenhum acesso a esse "sexo" exceto por meio de sua construção, então parece não apenas que o sexo é absorvido pelo gênero, mas que o "sexo" torna-se algo como uma ficção, talvez uma fantasia, retroativamente instalado em um local pré-linguístico ao qual não existe nenhum acesso direto (BUTLER, 2010, p. 158).

A partir do momento em que a distinção sexo/gênero, natureza/cultura são abolidos, então eles podem ser usados quase como imbricações, ambos podem ser compreendidos como uma formulação performativa que produz as diferenças sexuais na modernidade.

Essa compreensão possui uma contraface política de grande relevância para nosso estudo, a saber: a partir do momento que suspendemos a predominância verdadeira dos polos sexo e natureza em oposição aos polos gênero e cultura, passamos a perceber como são artificialmente construídas as normas e as leis da heterossexualidade. Compreendemos que tais normas são construídas a partir de um imperativo linguístico, ou seja, de estruturas discursivas, científicas e epistemológicas que induzem o sujeito/sujeitado a se compreender como um Homem ou uma Mulher (com H e M maiúsculos), justamente aqueles tomados por Connell em sua conceituação de masculinidade. Tal indução se dá a partir do momento em que a ideia de natureza do corpo - e consequentemente do sexo - são assimilados pelo sujeito/sujeitado de forma a constituir-se subjetivamente. Nas palavras de Butler:

O regime da heterossexualidade atua para circunscrever e contornar a "materialidade" do sexo e essa "materialidade" é formada e sustentada através de - e como - uma materialização de normas regulatórias que são, em parte, aquelas da hegemonia sexual [...] a materialização de normas exige aqueles 


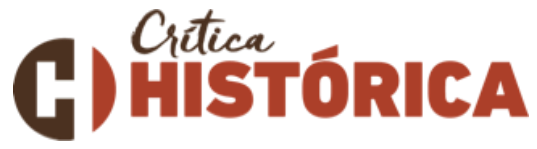

processos identificatórios pelos quais as normas são assumidas ou apropriadas, e essas identificações precedem e possibilitam a formação de um sujeito (BUTLER, 20IO, p. I70).

Com isso, Butler afasta as teorias biologicistas, puramente materialistas ou essencialistas de um homem ou uma mulher que sejam universais e anteriores aos discursos que os/as constituíram. Por tal procedimento a modernidade ocidental produziu e estimulou um regime da heterossexualidade e fez surgir e se opor - junto das figuras aberrantes da sexualidade - duas subjetividades e práticas, consideradas socialmente ideais: o homem e a masculinidade; e a mulher e a feminilidade.

Por meio dessa conceituação Butler nos permite compreender os procedimentos pelos quais se estabelecem as hierarquias de gênero, não necessariamente explicando seu funcionamento simbólico interno, mas antes permitindo o estabelecimento das linhas mestras de sua construção e, consequentemente, abrindo os horizontes para sua desconstrução. Importante lembrar que o conceito de desconstrução de Butler é tributário ao de Jaques Derrida, que não se refere a ele como mera destruição ou implosão, antes disso, como uma sequência de regras, compreendendo as estruturações internas da constituição de um jogo textual de escritura e significação (SALLIS, 1987). Nesse sentido, compreender a construção e a desconstrução da masculinidade, enquanto subcategoria dessa estrutura subjetiva elencada pelo par sexo-gênero, significa perceber as formas pelas quais ela se edifica - seja por meio da análise literária, histórica ou política - de maneira a explicitar a inexistência de elementos de eternidade, naturalidade ou inquestionabilidade.

A primeira questão que se dele refere-se à questão metodológica da reiteração e citacionalidade, como já estabelecido por Jacques Lacan (2005), se a lei se estabelece a partir de sua citação ou nomeação (o nome do pai) então para que ela se estabeleça ela precisa ser constantemente reforçada, reiterada e citada infinitamente, até que a mentira contada por cem vezes se torne verdade e assuma o caráter de força de lei (DERRIDA, 20I8), dessa forma a nomeação reiterada de uma subjetividade a constitui enquanto padrão, normatização, normalização e condução de condutas. Nesse sentindo a masculinidade não se apresenta como algo pré-linguístico, mas antes, como efeito dessa nomeação. Em outros termos, não há nenhuma vivência social que atravesse a todos os indivíduos do sexo masculino em uma 
sociedade, a não ser, a relação de aceitação ou negação da norma/lei que o nomeia enquanto homem. Essa nomeação não é um simples momento de batismo, mas antes, uma sequência de afirmações serialmente repetidas que permitem que haja um processo de autoinserção no interior daquela trama linguística. Trata-se de uma membrana simbólica que encobre corporalidades, pensamentos, formas de agir e falar que os modela em escala individual e coletiva, a todos e a cada um, omnes et singulatim (FOUCAULT, I990). A norma linguística nesse sentido precederia as práticas, uma vez que sua concepção já estaria arraigada no interior das percepções simbólicas e cognitivas daqueles que são falados pelas palavras que falam. Pensar desta forma a masculinidade nos permite compreender a importância dos discursos e da citação reiterada de suas normas como constituinte de seus próprios princípios básicos, e, nesse sentido encena-se uma forma de construção dos sexos, segundo a teoria butleriana. Por outro lado, essa construção quando compreendida nesses termos demonstra fragilidade ímpar, uma vez que aquela significação que acreditávamos eterna e estrutural transforma-se em algo absolutamente quebradiço, como um tecido feito de palavras transparentes, que constituem uma masculinidade-rei que sempre esteve nua, mas ninguém ousava questionar sua nudeza dada sua autoridade e o medo da punição simbólica e material.

A percepção linguística da sexualidade enreda uma continuidade bastante ativa, agenciadora, política e politizada de compreensão das hierarquias e relações de poderes no interior dos sexos e das subjetividades sexuadas. Uma vez que a sexualidade enquanto corporalidade é nomeada linguisticamente, isso significa que as experiências práticas do corpo, da mente e das condutas masculinas seriam formas de interpretação, baseadas na introjeção da norma, compatibilização com seu ideal de eu e posterior calcificação identitária, tal como uma máscara rígida. Nesse sentido ninguém melhor que Fernando Pessoa para resumir esse processo em uma brilhante estrofe do poema Tabacaria:

\section{O dominó que vesti era errado}

Conheceram-me logo por quem não era e não desmenti, e perdi-me

Quando quis tirar a máscara

Estava pegada à cara

(PESSOA, 2016, p. 246)

Essa máscara pegada à cara mostra-se como a própria face individual de um homem passa a tornar-se modelo, significa o modelo, se identifica com os contornos do padrão ou do 


\section{C) HitșTórICA}

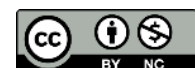

padrão de homem. É esse o momento em que o processo de subjetivação se dobra de fora para dentro, de uma simples imagem física e fugidia passa a internalizar aquela imagem junto do olhar que o define - o Outro de Lacan (SAFATLE, 2007). Nesse sentido, vivemos em um grande baile de máscaras em que várias faces são encenadas numa espécie de teatro com roteiros incertos e atuações tragicômicas. Consideramos que o tema central da violência e da masculinidade quando pensados a partir dessa matriz pode ganhar novos contornos, uma vez que essa aterrorizante encenação coletiva da posse e do ciúmes é cada vez mais reificada pelas assertivas de poder e força às personagens agirem sob esse macabro papel, obviamente isso não lhes tira a culpa ou o poder da negação - onde há poderes há resistências (FOUCAULT, 1979) porém, isso demonstra o caráter mais resolutivo da teoria butleriana e que também pode se tornar uma das mais promissoras possibilidades de ranhuras e linhas de fuga no interior desse sistema normatizador, trata-se do conceito de performatividade.

Segundo a teoria de Butler o gênero não é identitariamente colado mas é encenado, vestido, despido e redescoberto em cada ato, inclusive ato de fala. Se em nossa narrativa parece que surge uma camisa de força de uma máscara pré-encaixada no rosto, de um papel adscrito em roteiros pré-definidos, então precisamos compreender a contraface do conceito de performatividade que, também pode ser realizada de forma absolutamente arbitrária a tais normatizações sociossexuais. O exemplo mais trabalhado por Butler é justamente a imagem da drag queen, uma vez que sua performance tenciona as fronteiras daquilo que é considerado masculino e feminino, subvertendo com seu corpo híbrido essa própria dicotomia. A drag não pode ser excluída do teatro das masculinidades, talvez a mais desviante e extravagante delas, mas essa constituição também é válida para refletirmos acerca da masculinidade normatizada e normalizada, afinal, se não existe um local da neutralidade nesse teatro, também o masculino é uma roupagem ou um papel a ser interpretado e performatizado teatralmente, em que se demandam jogos de encenação e apropriado desempenho corporal-expressivo de maneira a convencer a plateia de seus valores e atributos considerados hierarquicamente superiores.

Dessa maneira, não é necessário alcançarmos exemplos extra sociais para compreende o queer (aqueles sujeitos avessos e até mesmo excluídos das normatividades sociais), Eve Segdwick (2008) em seu brilhante ensaio sobre a epistemologia do armário levanta a questão de que não há um espaço de normalidade no campo dos desejos. Todos os seres possuem suas mais profundas perversões, inspirações e bizarrices em geral, de forma que ninguém é adscrito numa 


\section{G) hitsisónica}

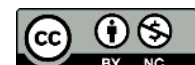

esfera da completa normalidade, por isso vivemos numa sociedade completamente colocada no interior do armário, que não consegue se libertar e sair do armário. Ou seja, a teoria queer não trata apenas de sujeitos minoritários específicos que não se encaixam na continuidade sexo-corpodesejo, pelo contrário, opera em escala massiva pela esmagadora maioria da população (para não dizer a totalidade) - homens e mulheres moldados física e psicologicamente pelo ocultamento dos seus desejos relegados à esfera da obscenidade.

Também podemos aludir às leituras de Sigmund Freud e seu mal-estar na civilização (20I0) ou à Norbert Elias em seu Processo Civilizador (1994) quando postulam que a compreensão ocidental de civilização/cultura se baseia na capacidade - especialmente masculina - de saber comedir e reprimir seus impulsos instintivos - que para ambos os pensadores são violentos, naturais e inerentes da espécie humana - porém o próprio Freud nos fala que trata-se de um esquema indigesto para aquele psiquismo uma vez que o elemento reprimido retorna incessantemente. Não se trata de psicologização ou sociologização do argumento, antes disso, essas teses freudianas do social, questionáveis em muitos pontos, nos permitem compreender que também a heterossexualidade e sua defesa dependem de processos de repressão, autoanulação e controle de pulsões - independentemente do fato delas serem naturais/inatas ou artificiais e linguisticamente construídas. Apesar do fato de que a teorização queer serve sobremaneira para conceber os meandros da população trans, socialmente vista como o outro do outro, tais sentenças também podem, e devem, ser aplicadas às subjetivações masculinas, afinal de contas, aquilo que Robert Bly e seus guerreiros faziam nos fins de semana (I990) nada mais era do que uma performance de gênero absolutamente próxima da drag queen, com a notória diferença da carga misógina e preconceituosa que a primeira possuía com relação à segunda.

Isso é deveras interessante pela possibilidade analítica de comparar-se voltas metrossexuais, músculos de academias de ginástica, bigodes de clubes de tiro com as unhas postiças, perucas viçosas e batons de cores vibrantes usados pelas drags. Compreender a masculinidade como performance é, por si só, uma via de desconstrução do masculino. Porém, reforçamos que não podemos utilizar o conceito como uma moeda de troca comum utilizável a todos os contextos, é necessário que haja sensibilidade empírica de adaptação. Por exemplo, talvez a masculinidade para um aborígene da micronésia não possua (certamente não possui) as mesmas conotações ocidentais performativas da subjetivação baseadas na norma ocidental. 


\section{G) GitsTórilcA}

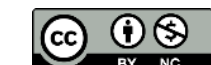

Portanto, reforçamos que sob um mundo pós-colonial não há chave mestra para compreender o gênero e a performatividade, pode-se utilizar a noção por sua via de flexibilidade e desconstrução, sendo mais maleável que o igualmente adaptável conceito de masculinidade hegemônica. Importante é que se compreendam os contextos de produção contextual e sua sintonia com os contextos dos objetos de pesquisa.

\section{O retorno transformado de Connell e as estruturas de Butler - Confluências (não admitidas)}

Como proposta, nosso artigo aventa para alguns possíveis pontos de diálogo entre as autoras - de um diálogo que não existe na prática - sem a pretensão de que haja confluência de ideias de ambas as teóricas que pouco se comunicam. Nos interessa mais criar convergências teóricas, dobras de pensamento para que os estudos das masculinidades possam se apropriar de elementos interessantes de ambas sem rechaçar, de antemão, uma ou outra.

Talvez o grande equívoco de criticarmos anteriormente a fixidez das categorias connellianas tenha se dado pela tentativa de realizar uma leitura identitária de uma autora literal e figuradamente trans, isto é, uma autora que, pelo menos biograficamente falando, não é nem um pouco apegada em estruturas de identidade fixa ou cristalizações binárias. Isso fica muito claro em seus estudos mais recentes que, além de ampliar as esferas de atuação e compreensão do masculino enquanto teoria mutável e relacional - histórica e geograficamente - também se interessa por outras transversalidades que constituem estruturações de gênero distintas na contemporaneidade. Nesse sentido, Raewyn Connell em seus estudos mais recentes (20I5 e 2016) foca em três eixos principais de atuação que trazem novo fôlego para o campo disciplinar, para além daquela conceituação adjetivante e categorizante das quais esboçamos críticas anteriormente. Tais eixos são: a crítica pós-colonial do gênero a partir das epistemologias do sul; a crítica ao capitalismo financeiro por meio da ampliação global e universalização de suas estruturas culturais (que enquanto tal são sempre políticas) bem como a imposição de padrões masculinos constitutivos de um novo patriarcalismo contemporâneo e, por último, a questão das mulheres transexuais em sua delicada relação com a sociedade capitalista modeladora/excludente e também com relação ao feminismo identitário, que muitas vezes insiste na tônica de que mulheres trans não possuem experiência de gênero femininas e não podem compartilhar das pautas e demandas do feminismo. Dessas três perspectivas, todas absolutamente pertinentes para a redefinição de uma pauta sobre os estudos masculinos e de 


\section{C) GitsisTórICA}

gênero como um todo, nos permite compreender a constituição de certo aprofundamento político e teórico que sobrepõe a estruturação de um esquema interpretativo focado nas masculinidades hegemônicas. Para além disso, mesmo sem negar as perspectivas anteriores, Connell considera que

Precisamos melhorar a forma como as análises de gênero têm sido feitas. Boa parte das pesquisas sobre gênero se baseia numa abordagem fundamentalmente estática e categórica. Segundo essa abordagem, o gênero envolve duas categorias, masculino e feminino, e falar em gênero é falar sobre a diferença entre essas categorias [...] é preciso que ultrapassemos concepções unitárias sobre o sujeito do feminismo. [...] O que as teorias do gênero ainda não compreendem bem é que as dinâmicas de gênero tomam formas específicas em contextos coloniais e pós-coloniais, pois, como aponta Lugones, estão entrelaçadas às dinâmicas de colonização e globalização (20I6, p. 29-3I).

Esse crescente interesse pela compreensão da epistemologia pela perspectiva do sulmundial e das mulheres trans aproxima Connell a uma ótica global, mas não universalista, interessando-se sobremaneira por experiências de pessoas deslocadas, excedentes, subjetivamente questionadoras das normas estabelecidas de poder, gênero e hierarquia. Mais que isso, seu próprio conceito de gênero passa a se ampliar e abranger feministas para além da margem euro-estadunidense, considerada fundadora dos principais pilares do feminismo. Nesse sentido sua posição é de um contextualismo bastante extremo, reforçando a incapacidade das teorias feministas do eixo norte do mundo responderem a questões dos países pobres e em desenvolvimento do sul mundial - ironicamente a Austrália de Connell pode ser considerada uma exceção a essa regra, por mais que seja um país geograficamente situado em alinhamento paralelo com a América do Sul e África, economicamente se encontra numa posição de grande superioridade. É justamente pela perspectiva pós-colonial que Connell assume uma condição mais antropológica em suas pesquisas, enriquecida pela multiplicidade de abordagens contextuais da masculinidade exercidas em diferentes culturas, por outro lado, sua proposta ainda não abre mão do conceito de identidade, talvez o maior alvo político das pesquisas de Butler. É nesse sentido que Connell tece suas críticas:

O trabalho de Butler continua a demandar atenção e a guiar os trabalhos atuais sobre transgeneridade. No entanto, as condições do envolvimento de Butler 


\section{(C) hitșTórica}

com a transexualidade são problemáticas, como a crítica de Namaste demonstra. Ele se apoia na apropriação da experiência de pessoas transexuais e transgênero que, para focar na subversão da identidade, ofusca as realidades econômicas do drag e da prostituição, o caráter específico do gênero da violência, e a devastação das vidas de mulheres transexuais (2016, p. 232).

Essa crítica aparenta uma característica praticamente falaciosa, uma vez que se coloca as pesquisas de Butler como "problemáticas" a partir de trabalhos de outros pesquisadores inspirados na perspectiva teórica da autora. Mais que isso, é notório que a crítica da identidade não apresenta nenhuma relação de ofuscamento de realidades econômicas, prostituição e violência. Pelo contrário, o elemento simbólico e discursivo sendo percebido como performativo permite que se questione justamente essas realidades. Na verdade, o problema todo consiste no preconceito que pesquisadores assumem ao campo pós-estruturalista como esfera do puramente discursivo, como se discurso fosse dicotomicamente avesso à realidade (ALBUQUERQUE JÚNIOR, 2006) ou como se subjetividade fosse dicotomicamente avessa à identidade. Podemos afirmar que a teoria de Butler não se trata de pura poesia ou "determinismo linguístico antibiologicista sem remissão que consistiria em sustentar que tudo, inclusive o corpo, é linguagem ou que não há nada mais que a substância das palavras" (DÍAZ, 20I3, p. 4II). Antes de negar a existência do corpo e do sujeito, Butler busca compreender de que forma eles são construídos, não enquanto carne, mas a partir de normas e mecanismos simbólicodiscursivos que são absolutamente produtivos daquilo que nomeiam, ao extremo, também são (f)atos sociais. Nesse sentido, a preocupação de Butler não é esterilizar ou ofuscar as violências de gênero, pelo contrário, é compreender como a constituição de um limite entre o normal e o inaceitável, o humano e o bárbaro, o moral e o imoral são traçados constituindo subjetividades marcadas com a insígnia da exclusão:

The debate between constructivism and essentialism thus misses the point of deconstruction altogether, for the point has never been that "everything is discursively constructed"; that point, when and where it is made, belongs to a kind of discursive monism or linguisticism that refuses the constitutive force of 


\section{C) GitsisTórica}

exclusion, erasure, violent foreclosure, abjection and its disruptive return within the very terms of discursive legitimacy. (BUTLER, I993, p. 8)

Novamente Lacan é invocado para que tais estruturas subjetivas sejam compreendidas não por uma via libertária da poetização das vivências, mas, pelo contrário, por uma compreensão normativa do estabelecimento de forclusão, aquela atitude psicótica que rejeita um significante para o exterior do universo simbólico do sujeito ou da sociedade. Não se trata simplesmente de repressão uma vez que, psicanaliticamente falando, o reprimido sempre retorna. O forcluído é a pura abjeção, ao ponto do esquecimento, que por uma perspectiva biopolítica pode ser compreendido como aquele deixado a morrer, legítimo homo saccer (AGAMBEN, 2012). Não bastando isso, Butler trabalha com outro mecanismo nesse ínterim, em que a própria normalidade ou a heteronormatividade é constituída exatamente pela exclusão a essa norma. O vexamento é elemento constitutivo não apenas da exclusão, mas, principalmente, da norma e da subjetividade normal a partir da oposição simétrica com aquilo que nega. É claro que Butler está pautando própria construção da subjetividade trans e sua existência enquanto borradora desses limites discursivos de gênero. Mas, novamente, se considerarmos o gênero enquanto produção performativa e social podemos compreender o masculino como referente direto à trans, justamente porque se constitui no interior da exclusão, da negação, da rejeição. Evidentemente que por uma perspectiva hierárquica distinta, uma vez que, na linguagem freudiana, o masculino introjeta o objeto oposto ao negado para o interior de seu ideal de eu, ao passo que a trans o renega, satiriza, ironiza e burla justamente por sua existência.

São exatamente esses mecanismos de rejeição do outro e reforço do eu/nós masculinos que, nas próprias teorias de Connell, constituem a masculinidade enquanto estrutura gênero em que homens se modelam por meio da negação e afastamento não apenas da feminilidade mas também daquele outro pouco masculino ou não virilizado (2003). Seja pela perspectiva linguística da performatividade, seja pela perspectiva social das masculinidades hegemônicas, tanto Butler quanto Connell estão preocupadas em estabelecer uma crítica mordaz à construção

\footnotetext{
7 Tradução do autor: "O debate entre o construtivismo e o essencialismo passa completamente por alto pela questão essencial da desconstrução, porque a questão essencial nunca foi a de que "tudo é discursivamente construído"; essa questão essencial, quando se propõe, corresponde a uma espécie de monismo discursivo ou linguisticismo que nega a força constitutiva da exclusão, a supressão, a forclusão e a abjeção violenta e seu retorno destrutivo dentro dos termos mesmos da legitimidade discursiva".
} 


\section{C) GitsisTórICA}

de estruturas de gênero que fazem da subjetividade masculina ocidental-branca-capitalista-cishétero-burguesa o maior desastre psicossocial já conhecido, justamente porque institui modelos de relação com o outro, o Outro, a outra e os outros objetos de oposição, exclusão, violência e, até mesmo, extermínio. Não por acaso Butler é uma pensadora da ética, comentadora de Hannah Arendt e Theodor Adorno: sua perspectiva de interação social é evidente, não se trata de simplesmente tolerar as diferenças (BROWN, 2008), ou de marcar uma relação automática entre masculinidade e violência, trata-se de inserir a alteridade no interior de um jogo ético para que ela seja constitutiva de subjetividades fundadas numa identidade que não opere sob a insígnia da pura exclusão da diferença, da violência ou do vexamento mas, pelo contrário, que se abram possibilidades de constituição e existência biológica e subjetiva de sujeitos outros, que possam assumir vivências fluidas sem serem previamente rotulados ou categorizados moralmente, que não sejam forçosamente pautados na pura marca nominal da heteronormatividade. Essa perspectiva não é oposta, pelo contrário, é absolutamente dialógica com as posições connellianas quando demanda novas políticas de inclusão e diálogo com as distintas expressões e vivências de corpos e simbolizações de gênero.

Novas formas de aprendizagem de ativismo podem acontecer. Os grupos marginalizados se mobilizam dentro de tradições diferentes do ativismo popular e enfrentam diferentes ambientes religiosos, de poder estatal e prática de gênero. [...] Falar nesses termos de "outras políticas" é algo otimista; mas precisamos de um pouco de otimismo a partir da determinação. As velhas políticas identitárias e excludentes causaram uma divisão entre o feminismo e as mulheres transexuais que ainda não foi superada completamente. [...] $\mathrm{A}$ direção política sugerida [...] tem o prospecto do envolvimento de pessoas transexuais feministas com outras feministas ativas que podem conseguir ganhos práticos para justiça de gênero, e enriquecer o feminismo como um todo (CONNELL, 20I6, p. 253)

É claro que a perspectiva de Connell é mais engajada enquanto a de Butler é mais reflexiva, muito embora o engajamento da primeira não se furta à reflexão e a reflexão da segunda não prescinde do engajamento. Porém, se levadas ao extremo, ambas as perspectivas são - à sua maneira - politicamente potentes e eticamente necessárias para que se evite a onda de transfobia, homofobia, lesbofobia, machismo e misoginia que se vive contemporaneamente. Não se trata apenas de defender dicotomicamente o feminismo trans em contrariedade ao 


\section{C) HitșTórICA}

feminismo identitário - que é um dos principais argumentos da obra Problemas de Gênero (20I9), trata-se de uma aposta coletivista de construção de novos sentidos políticos e estruturas reprodutivas dos significados e práticas de gênero, seja em sua perspectiva performática seja sob a ótica das ações (BUTLER, 2018). Em ambas as teóricas se estabelece uma crença na possibilidade política do diálogo e da resolução de problemas subjetivos por meio da política, em sua acepção aristotélica, de discussão entre pares (BUTLER, 20I9). Nesse sentido, a discussão metodológica entre a compreensão (pré)discursiva e performativa do gênero ou as leituras pósdiscursivas e práticas de gênero se torna menos importantes tendo em vista o compartilhamento de uma pauta política comum.

\section{Considerações finais}

Tanto as teorias de Butler quanto as de Connell buscam, implícita ou explicitamente, a instituição de novas narrativas, que constituem sujeitos por matrizes diferentes das quais vivenciamos no contexto capitalista ocidental. Mesmo a sociologia de Connell, que critica as posições linguísticas, não se furta a afirmar que "reconhecer narrativas alternativas de masculinidade, e diferentes maneiras de ser homem, é um passo crucial para as maneiras respeitosas de trabalhar com rapazes para reduzir a violência" (CONNELL, 20I6, p. I56) e arremata, a partir de comentário das pesquisas dos psicólogos discursivos Margaret Wetherell e Nigel Edley que "as masculinidades existem não como estruturas consolidadas de papéis, mas como posições imaginárias em um discurso. Homens, na prática, usam essas posições estrategicamente, por vezes adotam-nas, por vezes distanciam-se delas” (2016, p. 157). Mesmo que para Butler não haveria um homem anterior à sua (auto)formulação que tomaria ações a partir de um eu já constituído, é possível encontrar similitudes numa perspectiva que clama por subjetividades e sociabilidades masculinas não violentas e mais hospitaleiras com relação à diferença. Isso resolve alguns dos principais pontos dos nossos questionamentos iniciais acerca de uma masculinidade adjetivada, talvez Butler nos proponha a possibilidade de pensar em uma ou várias masculinidades subjetivadas, e assim podemos compreender adjetivações sob o ponto de vista sociológicos e subjetivações do ponto de vista filosófico, para que assim possamos nos aproximar, ainda que de maneira incipiente, a um conceito de masculinidade. 


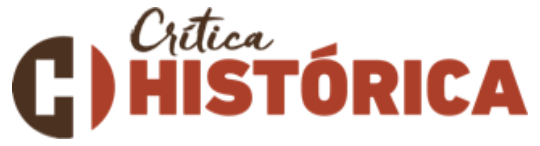 \\ Referências}

AGAMBEN, Giorgio. Homo Sacer: O poder soberano e a vida nua I. Belo Horizonte, Editora UFMG, 2012.

ALBUQUERQUE JÚNIOR, Durval Muniz. Nos Destinos de Fronteira: História, espaços e identidade regional. Recife: Edições Bagaço, 2008.

O historiador Naif ou a análise historiográfica como prática de excomunhão. In: GUIMARÃES, Manoel Luís Salgado (Org.). Estudos sobre a escrita da história. Rio de Janeiro: 7Letras, p. 193-215, 2006.

Nordestino: Uma Invenção do Falo. Maceió: Edições Catavento, 2003.

ARISTÓTELES. Obras Completas - Política. São Paulo: Edipro, 2019.

AUSTIN, John Langshaw. Cómo hacer cosas con palabras. Buenos Aires: Paidos, 2016

BOTTON, Fernando Bagiotto. O homem da imagem e a imagem do homem: a construção da subjetividade masculina por meio dos retratos e periódicos de Curitiba na virada do século XIX para o XX. História, Universidade Federal do Paraná. Curitiba, 2013.

BEAUVOIR, Simone de. O segundo sexo. Rio de Janeiro: Nova Fronteira, 2012.

BLY, Robert. Iron John: A Book about Men. Jackson: Da Capo Press, I990.

BOURDIEU, Pierre. A dominação masculina. Rio de janeiro: Bertrand, I997.

BRICKELL, Chris. Masculinities, Performativity, and Subversion: A Sociological Reappraisal. In: Men and Masculinities, n. I, p. 24-43, 2005. Disponível em:

https://journals.sagepub.com/doi/IO.II77/I097184X032575I5 Acesso: 13/IO/2020.

BROWN, Wendy. Regulating Aversion: Tolerance in the Age of Identity and Empire. Princeton: Princeton University Press, 2008.

BUTLER, Judith. Bodies that matter: On the discursive limits of "sex". New York \& London: Routledge, 1993.

Routledge, 1990.

Gender Trouble: Feminism and the Subversion of Identity. New York \& London: Autêntica, 2010.

Corpos que pesam. In: LOURO, G. L. (org.) O corpo educado. Belo Horizonte:

Problemas de gênero: feminismo e subversão da identidade.I ${ }^{a}$ Ed. Rio de Janeiro: Civilização Brasileira, 20ı9. 


\section{G) Gitsistórica}

Corpos em aliança e a política das ruas: notas para uma teoria performativa de assembleia. Rio de Janeiro: Civilização Brasileira, 2018.

CECCHETTO, Fátima Regina. Violência e estilos de masculinidade. Rio de Janeiro: Editora FGV, 2004 .

CONNELL, Raewyn. Gênero em termos reais. São Paulo: nVersos, 2016.

Gênero: uma perspectiva global. São Paulo: nVersos, 2015.

CONNELL, Raewyn; PEARSE, Rebecca. Questões de gênero e justiça social. In. Século XXI, Revista de Ciências Sociais, v.4, $\mathrm{n}^{\circ}$ 2, p.II-48, $20 \mathrm{I} 4$.

CONNELL, Robert. Masculinidades. Ciudad de México: UNAM/PUEG, 2003.

Masculinities. Cambridge: Polity Press; Sydney: Allen \& Unwin; Berkeley: University of California Press, 1995.

Políticas da Masculinidade. In: Educação e Realidade, Porto Alegre. Vol. 20 (2), 1995.

CONNELL, Robert; MESSERSCHMIDT, James. Masculinidade hegemônica: repensando o conceito. Revista de Estudos Feministas, Florianópolis, v. 2I, n. I, p. 24I-282, 2013.

DERRIDA, Jacques. Limited Inc. Campinas: Papirus, I99I

Força de Lei. São Paulo: WMF Martins Fontes, 2018.

DÍAZ, Elvira Burgos. Desconstrução e Subversão: Judith Butler. In Sapere Aude. Belo Horizonte: UFMG, v.4, n.7, p.44I-464, 2013.

ELIAS, Norbert. O Processo Civilizador Vol. I: Uma História dos Costumes. Rio de janeiro: Jorge Zahar Editor, 1994.

FOUCAULT, Michel. As palavras e as coisas: uma arqueologia das ciências humanas. São Paulo: Martins Fontes, 2007.

Microfísica do poder. Rio de Janeiro: Edições Graal, 1979.

Omnes et Singulatim: Por uma Crítica da "Razão Política” In: Novos Estudos CEBRAP, n. 26, p. 77-99, I990.

FREUD, Sigmund. O mal-estar na civilização, novas conferências introdutórias à psicanálise e outros textos. In: Obras completas Vol I8. São Paulo: Companhia das Letras, 2010.

HAMLIN, Cynthia; VANDENBERGHE, Frédéric. Vozes do Sul: entrevista com Raewyn Connell. In. Cadernos Pagu, Campinas, n. 40, p. 345-358, 2013. 


\section{G) Gitson TrórICA}

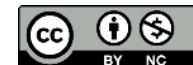

KELLER, Daniel; ARAÚJO, Denise Castilhos de. Masculinidades: identidade narrativa, performance e diagramas de marginalização. In: Caderno Espaço Feminino. Uberlândia: UFU, v. 30, n. I, p. 304-328, 2017.

KIMMEL, Michael. Manhood in America: A Cultural History. Ohio - USA: The Free Press, 2005.

LACAN, Jacques. Nomes-do-Pai. Rio de Janeiro: Zahar, 2005.

LAQUEUR, Thomas. Inventando o Sexo: Corpo e Gênero dos Gregos a Freud. Rio de Janeiro: Ed. Relume Dumara, 200I.

MACINNES, John. The end of masculinity. Philadelphia: Open University Press, I998.

MATOS, Maria Izilda. Meu lar é o botequim: alcoolismo e masculinidade. $2^{\mathrm{a}}$ ed. São Paulo: Companhia Editora Nacional, 200I.

MONTEIRO, Markos. Tenham Piedade dos Homens! Masculinidades em mudança. Juiz de Fora: FEME, 2000.

OLIVEIRA, Pedro Paulo de. A construção social da masculinidade. Belo Horizonte: Editora UFMG; Rio de Janeiro: IUPERJ, 2004.

PESSOA, Fernando. Tabacaria. In: Obra Poética de Fernando Pessoa. Vol 2. Rio de Janeiro: Nova Fronteira, 2016.

RODRIGUES, Carla. Performance, gênero, linguagem e alteridade: J. Butler leitora de J. Derrida. Sexualidad, Salud y Sociedad - Revista Latinoamericana, n.IO, p. I40-I64, 2012.

SAFATLE, Vladmir. Lacan. São Paulo: Publifolha, 2007.

SALLIS, John. Deconstruction and Philosophy: Texts of Jacques Derrida. Chicago: Chicago University Press, I987.

SEDGWICK, Eve Kosofsky. Epistemology of the Closet. San Francisco: University of California Press, 2008.

SOUZA, Rolf Ribeiro de. A confraria da esquina: o que os homens de verdade falam em torno de uma carne queimando. Etnografia de um churrasco de esquina no subúrbio carioca. Rio de Janeiro: Bruxedo, 2003.

WHITE, Hayden. The Practical Past. Evanston: Northwestern University Press, 2014. 


\section{C) GitcastórRICA}

Recebido: 15 de outubro de 2020

Aprovado: 02 de novembro de 2020

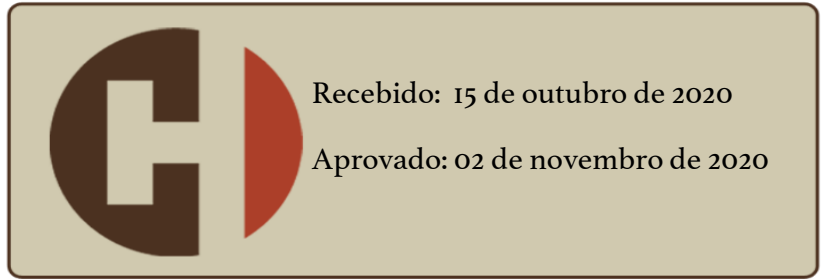

